\section{A New Species of Laelaps Koch (Acari: Laelapidae) Associated with Red Spiny Rat from Yunnan Province, China}

\author{
Pei-Ying Peng1,2, Xian-Guo Guo ${ }^{1,2, *}$ and Dao-Chao Jin ${ }^{2}$ \\ ${ }^{1}$ Vector Laboratory, Institute of Pathogens and Vectors, Dali University, and the \\ Yunnan Provincial Key Laboratory for Zoonosis Control and Prevention, Dali, Yunnan \\ Province 671000, P.R. China \\ ${ }^{2}$ Institute of Entomology, Guizhou University, The Provincial Key Laboratory for \\ Agricultural Pest Management in Mountainous Region, Guiyang 550025, P.R. China
}

\begin{abstract}
A B S T R A C T
A new species of gamasid mite, Laelaps jinghaensis sp. nov., was described. The new species was collected from the body surface of red spiny rat, Maxomys surifer Miller, 1900 in Jingha, Yunnan province of southwest China. The sternal shield of L. jinghaensissp. nov. is deeply concave anteriorly with serrate internal sides. There are many distinct transverse lines in the presternal area where the sternal shield is deeply concave. By these morphological features, the new species can be easily identified and differentiated from some other laelaps.
\end{abstract}
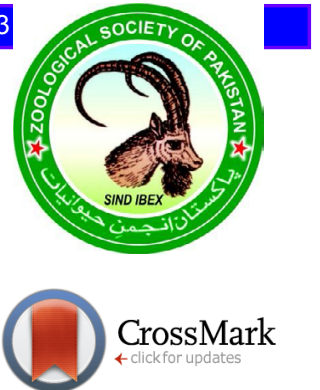

\begin{tabular}{l} 
Article Information \\
\hline Received 26 December 2017 \\
Revised 13 January 2018 \\
Accepted 18 January 2018 \\
Available online 18 May 2018 \\
Authors' Contribution \\
\hline XG was the leader of this project, \\
conceived the field investigation and \\
revised the manuscript. PP drew \\
the new species and drafted the first \\
version of the manuscript. DJ put \\
forward some suggestion about the \\
manuscript. \\
Key words \\
\hline Acari, Mesostigmata, Laelapidae, \\
Laelaps jinghaensis sp. nov.
\end{tabular}

\section{INTRODUCTION}

$\mathrm{L}$ aelapidae Berlese is a large and cosmopolitan family of gamasid mites in the order Mesostigmata, subclass Acari in class Arachnida, including hundreds of species (Pan and Deng, 1980; Deng et al., 1993). As a big group of arthropod, gamasid mites usually involve a diverse variety of habitats with different living behaviors, such as free living, predation and parasitism, etc. Apart from many species found in soil (Khan et al., 2017), plant debris, humus and even some warehousing goods (granary and flourmills), some gamasid mites (including laelapine mites in the family Laelapidae) can be ectoparasites, living on the body surface of vertebrates (mammals, birds, reptiles and amphibians, etc.) and even some other invertebrates (Pan and Deng, 1980; Deng et al., 1993; Lindquist et al., 2009). The ectoparasitic gamasid mites on rodents are of medical significance and some of them (i.e. Ornithonyssus bacoti, Laelaps echidninus and L. nuttalli) have been reported as attacking humans, resulting in varying degrees of dermatitis (Sandosham and Nordin, 1967; Nadchatram and Ramalingam, 1974). Some ectoparasitic gamasid mites (including laelapine mites) may have potentials to transmit or preserve the pathogens of some zoonoses (Zemskaya, 1973; Frolova, 1990). More than 20 kinds of

\footnotetext{
* Corresponding author: xianguoguo@yahoo.com 0030-9923/2018/0004-1279 \$ 9.00/0
}

Copyright 2018 Zoological Society of Pakistan zoonoses have been suspected to be related with gamasid mites (Chen and Xu, 1995). In China, some species of gamasid mites (including laelapine mites) have been proved to be the potential vector and reservoir host of hemorrhagic fever with renal syndrome (HFRS) and they may play an important role in keeping and extending the foci of HFRS (Baker et al., 1956; Deng et al., 1993; Song, 1999; Huang and Guo, 2010). HFRS is widely distributed in China, and the southwest China is an important focus of the diseases (Deng et al., 1993; Song, 1999; Huang and Guo, 2010). From 1990 to 2016, a series of field investigations on gamasid mites were made in Yunnan province, southwest China, and some results have been published, for example, the gamasid mites associated with the Asian house rat, Rattus tanezumi (Huang et al., 2013). From the collected specimens of gamasid mites in the above field investigation, a new species associated with red spiny rat (Maxomys surifer Miller, 1900) in Laelapidae was identified and named as Laelaps jinghaensis sp. nov. This paper described the morphological features of this new species of laelapine mites.

\section{MATERIALS AND METHODS}

In our field investigations from 1990 to 2016, the rodents and some other small mammal hosts were mainly trapped with mousetraps $(18 \times 12 \times 9 \mathrm{~cm}$, Guixi Mousetrap Apparatus Factory, Guixi, Jiangxi, China) from different localities in Yunnan province, southwest China. 

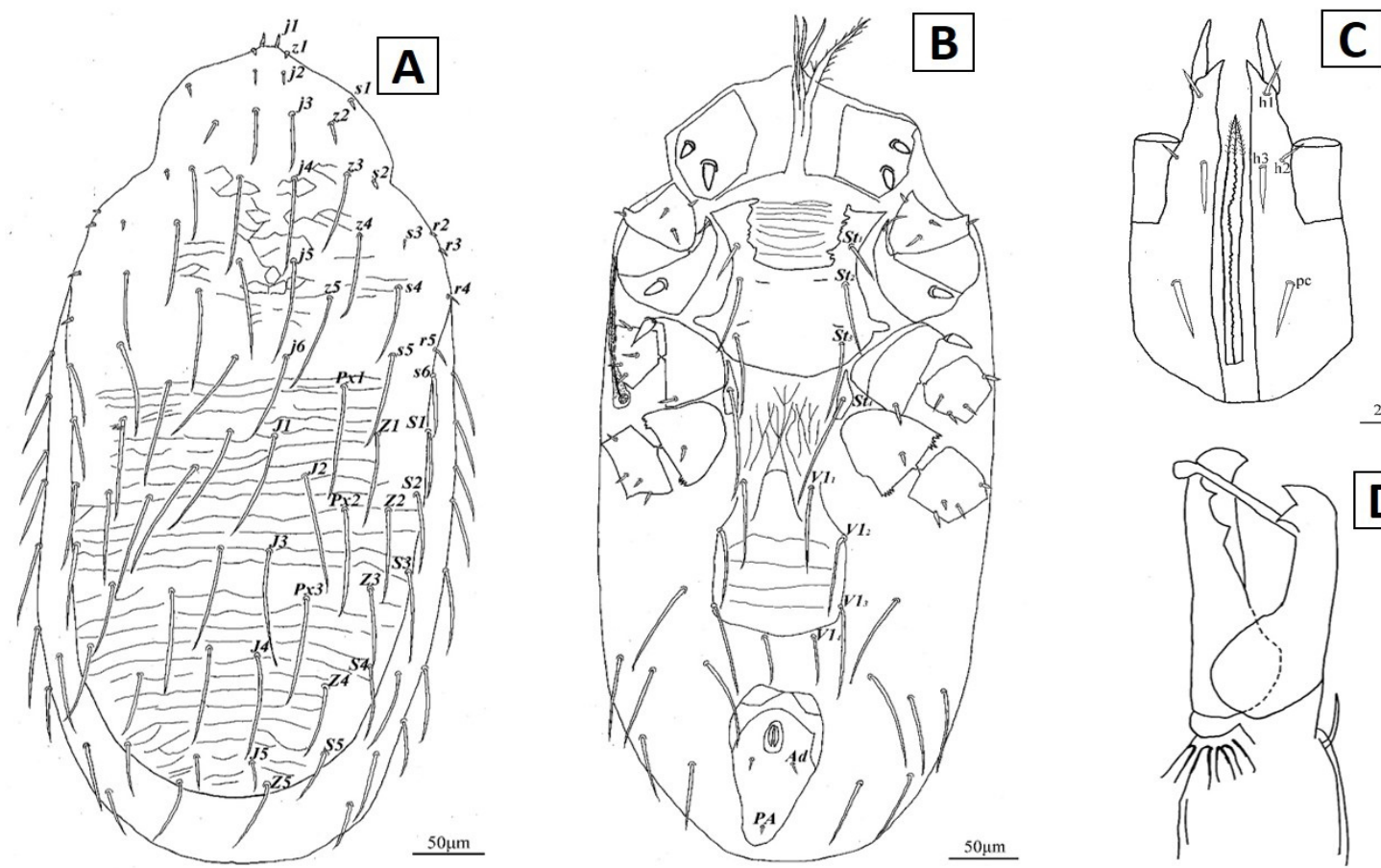

$\underline{20 \mu \mathrm{um}}$
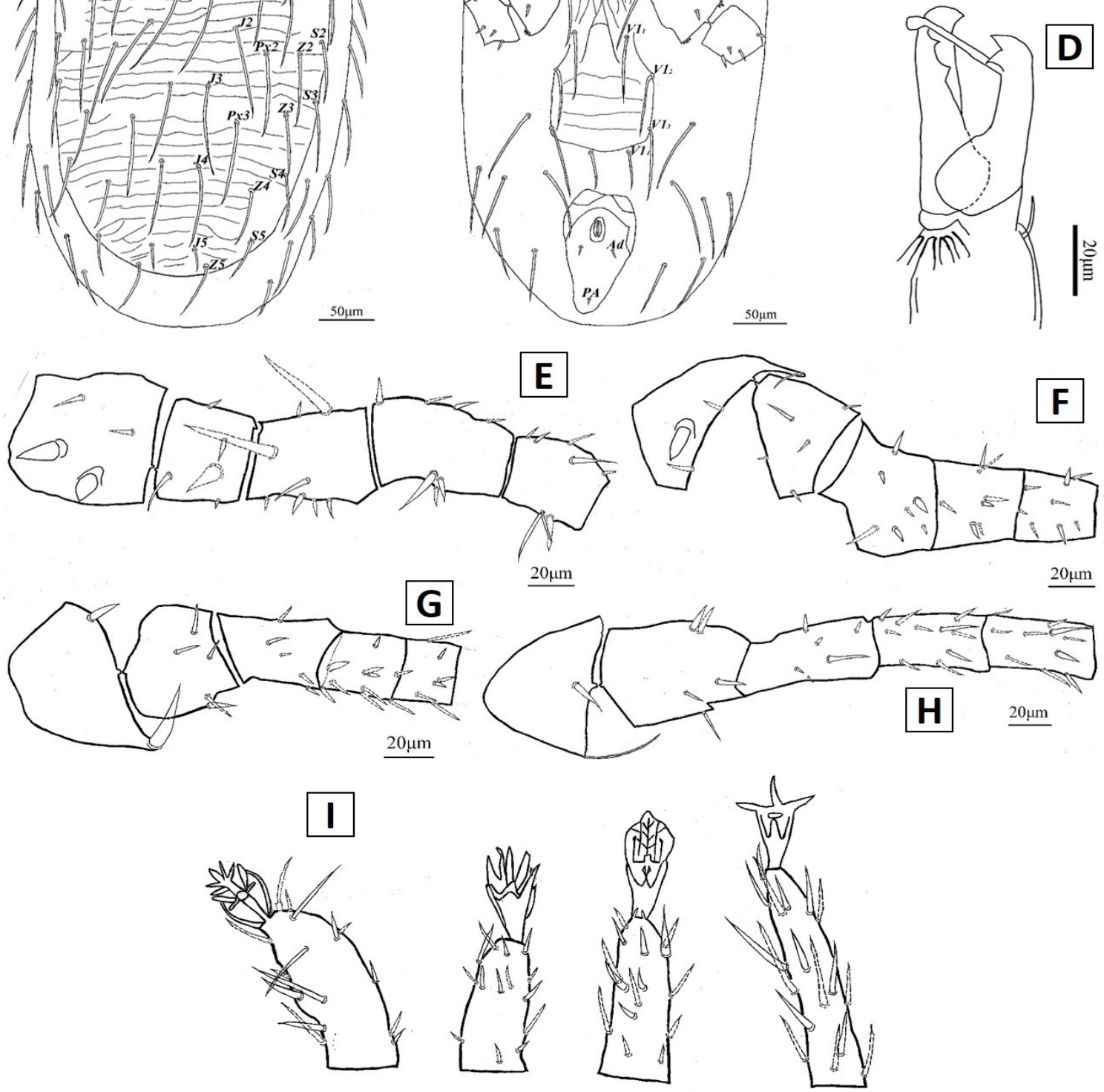

$20 \mu \mathrm{m}$

Fig. 1. Laelaps jinghaensis sp. nov.; Adult female: A, dorsal idiosoma; B, ventral idiosoma; C, gnathosoma, ventral aspect; D, chelicera; E, coxa, trochanter, femur, genu and tibia of leg I, ventral view; F, coxa, trochanter, femur, genu and tibia of leg II, ventral view; G, coxa, trochanter, femur, genu and tibia of leg III, ventral view; H, coxa, trochanter, femur, genu and tibia of leg IV, ventral view; I, tarsi of leg I-IV, ventral view. 
Every captured host was placed in a pre-marked white cloth bag and transferred to a laboratory where all hosts were anesthetized and identified to species following Wilson and Reeder (2005) for mammalian taxonomy. Gamasid mites were conventionally collected from each host (Guo et al., 2013). Gamasid mites on each host's body surface, together with those scattered on the white cloth bag, were comprehensively collected over a large white tray with the help of a magnifier. Those collected gamasid mites were preserved in vials with $70 \%$ ethanol and then mounted into glass slide specimens (Pan and Deng, 1980; Deng et al., 1993; Huang et al., 2013). The new species of laelapine mites reported in this paper was collected from the body surface of the red spiny rat (Maxomys surifer Miller, 1900) in Jingha, Yunnan province, southwest China, on the thirteenth of May 2016.

The specimens of the new species of laelapine mites were observed and measured under a Leica DM 3000 LED microscope. The morphological drawings of the new species were done by the help of the drawing instrument (Leica DM 3000 LED microscope) equipped with a drawing tube. The draft drawings were scanned and then embellished under the software Adobe Photoshop CS6. Measurements of structures are expressed as minimummaximum ranges in micrometres $(\mu \mathrm{m})$. The leg length was measured from the base of coxa to the apex of tarsus, including the pretarsus. The nomenclature used for the dorsal idiosomal chaetotaxy follows that of Lindquist and Evans (1965), the leg chaetotaxy follows that of Evans (1963), and the names of the pores on the dorsal shield follow Johnston and Moraza (1991). The holotype and paratypes of the new species and their hosts are deposited in the specimen repository of the Institute of Pathogens and Vectors, Dali University, P.R. China.

\section{RESULTS}

\section{Laelaps jinghaensis Peng and Guo sp. nov. (Figs. 1, 2)}

\section{Specimen examined}

The holotypes (a female and a male) were collected from the body surface of a red spiny rat (Maxomys surifer Miller, 1900) in Jingha (2150' N, 10052’E), Yunnan Province of southwest China in May 13, 2016, where the altitude is $640 \mathrm{~m}$.

\section{Paratypes}

Two females, same data as the holotype.

\section{Description}

Idiosoma

Colour orange-brown, oval shaped.
Dorsal idiosoma (Fig. 1A)

Body length 615-626 and width 284-303. Dorsal shield covering most of the idiosoma, length 536556 , width 248-254,sclerotized with distinct stripy and reticulate ornamentation on the whole shield, bearing 39 pairs of setae, 22 pairs on podonotal region $(j 1-6 ; z 1-5 ; s 1-$ 6 ; $r 2-5$; and $P x 1$ )and 17 pairs on opisthonotal region $(J 1-5$; Z1-5; S1-5; and Px2-3).Most setae long enough to exceed the base of posterior ones, and almost all setae needle-like. The shape, position and relative length of setae shown in Figure 1A. Measurements of dorsal setae: $j 1$ (5-10), j2(8-11), j3 (56-58), j4(75-77), j5 (77-79), j6 (74-77); 1 $(5-7), z 2$ (40-42), z3(60-63), z4(66-70), z5(78-81); sl(1114), s2(5-8), s3(7-10), s4(59-62), s5(71-73), s6(55-61); r2(7-16), r3(10-14), r4(11-19), r5(14-26); J1(82-86), J2(84-90), J3(83-85), J4(78-82), J5(27-29); Z1(75-78), Z2(72-76), Z3(69-73), Z4(59-63), Z5(54-59); S1(57-62), S2(61-66), S3(72-75), S4(70-75), S5(45-50); Px1(83-89), $\operatorname{Px2}(85-89), \operatorname{Px3}(79-82)$.

\section{Ventral idiosoma (Fig. 1B)}

Tritosternum with columnar base (125.4 long $\times 13.6$ wide) and pilose laciniae, length 65 (Fig. 1B). Presternal plates absent. Sternal shield length 129-135, width at narrowest part 90, with obviously deep concave anteriorly and slightly convex posteriorly; Two internal sides of the concave sternal shield are serrate. Many distinct transverse lines in the presternal area where the sternal shield is deeply concave. Posterior extension of sternal shield projecting slightly into the gap between coxae II and III. There are two pairs of lyriform organs and three pairs of needle-like sternal setae [St $(30-36), S t_{2}$ (54-60), $S t_{3}$ (60-66)], and $\mathrm{St}_{3}$ is the longest. Metasternal plate middle-sized, fusiform shaped, with one pair of setae $\mathrm{St}_{4}$ (80-85). Genitoventral shield vase-shaped, length (117120 ) and width (84-88), with a few irregular longitudinal lines on the anterior part and the anterior pair of diagonal lines forming an inverted "V" with smooth top, sclerotized with distinct stripy ornamentation on the posterior extension, bearing four pairs of setae $\left[V 1_{1}(64-71), V 1_{2}(55-\right.$ $\left.63), V 1_{3}(69-80), V 1_{4}(36-44)\right]$. The genitoventral shield expands exactly in the position of $V 1$, forming a vase-like shape. $V 1_{4}$ is not on the shield, but behind the posterior margin of the shield (adjacent to the posterior margin). Anal shield irregular inverted pear-like shaped, length (114-116), width (63-66), bearing a pair of short adanal setae $A d(8-12)$ and one tiny postanal seta $P A$ (6-8). Adanal setae $(A d)$ located behind the anal opening. Peritremes long, extending anteriorly around the margin of the dorsal shield and are fused with dorsal shield at level of coxa II.

\section{Gnathosoma}

Hypostome with three pairs of hypostomal setae 
[h1(13-18), h2(6-10), h3(13-16)] and a pair of palpcoxal setae (pc) (18-21) (Fig. 1C). Corniculi 22-26 long, robust and horn-like, parallel to each other, almost reaching midlevel of palp femur. Fixed digit of chelicerae, with one tooth, movable digit with two teeth of various size. The slender pilus dentilis on the fixed digit expands and bends in the end, which looks like a pipe (Fig. 1D).

\section{Legs (Fig. 1E-I)}

Legs II (279-295) and III (260-287) shorter than legs I (349-364) and IV (379-401). Chaetotaxy: Leg I: coxa $02 / 0$ $0 / 20$, trochanter $10 / 11 / 11$, femur $21 / 00 / 14$, genu $40 / 0$ $0 / 21$, tibia $30 / 20 / 0$; Leg II: coxal $1 / 01 / 10$, trochanter $10 / 10 / 21$, femur1 $0 / 13 / 20$,genu $12 / 02 / 20$, tibial $2 / 1$ 3/1 0;Leg III: coxa1 0/0 0/0 1, trochanter $1 / 10 / 20$, femur $12 / 0$ 0/1 1, genu $35 / 10 / 10$,tibial 2/1 0/1 1; Leg IV: coxa $00 / 10 / 00$, trochanter $01 / 10 / 21$, femur $03 / 01 / 20$, genu $15 / 12 / 10$, tibia $14 / 11 / 12$.

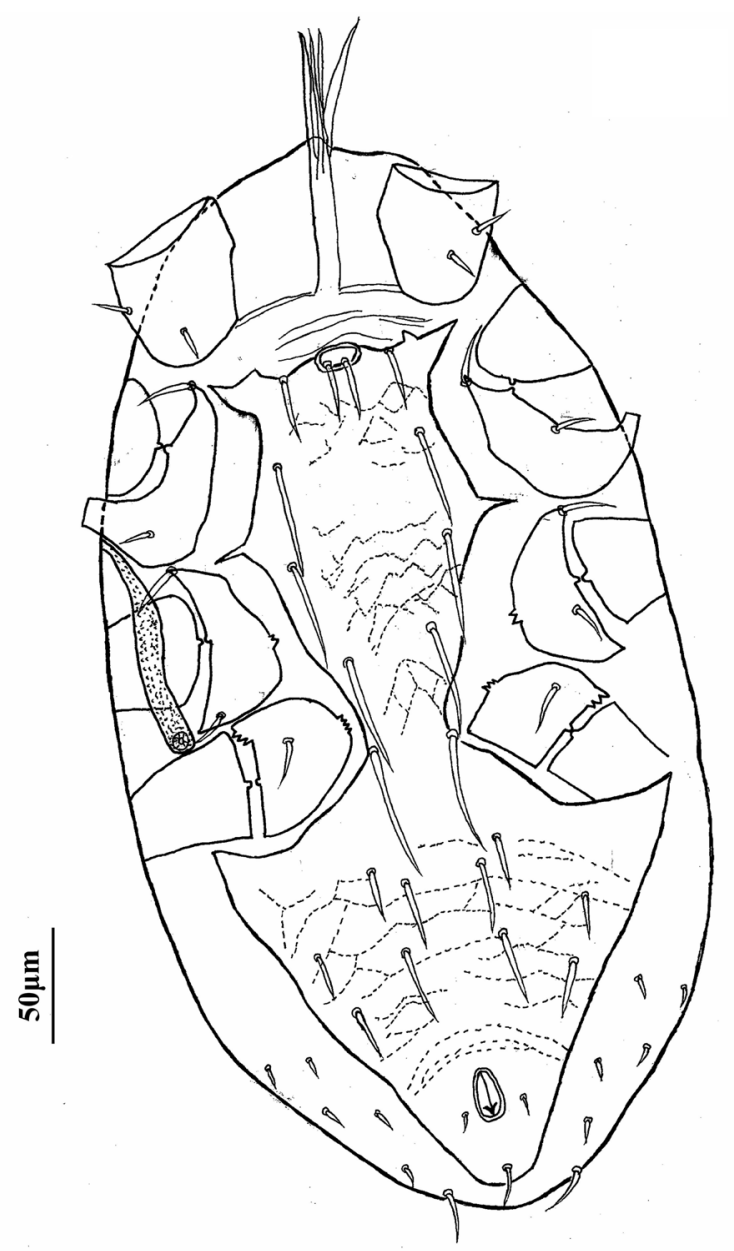

Fig. 2. Laelaps jinghaensis sp. nov., Adult male: ventral idiosoma.
Male

Ventral idiosoma (Fig. 2) holoventral plate not covering most of the ventral idiosoma, length 326 , width 164 in the widest, sclerotized with distinct reticulated ornamentation over $3 / 4$ surface. The holoventral plate expands in the coxa of the leg IV, bearing 10 pairs of setae except the adanal setae and postanal setae. The adanal setae are very short. Peritremes extend anteriorly around the margin of the dorsal shield and are fused with dorsal shield at level of coxa II.

\section{Etymology}

The new species is named after the collected area, Jingha, Yunnan province.

\section{Remarks}

The morphology of the new species is peculiar and unique, which is obviously different from some other species of laelaps. The coxa I of the new species, however, resembles that of Laelaps turkestanicus Lange, 1955, and these two laelapshave two thick ventral setae on the coxa I, but they can be easily distinguished each other by the characteristics of sternal shield. The sternal shield of the new species (L. jinghaensissp. nov.) is deeply concave anteriorly and slightly convex posteriorly, and there are many distinct transverse lines in the presternal area where the sternal shield is deeply concave. By contrast, the sternal shield of L. turkestanicus looks like a rectangle, which is very different from the new species, L. jinghaensissp. nov.

\section{ACKNOWLEDGMENT}

The authors would like to express our sincere thanks to Dr. Yi Yan (Shandong Agricultural University); Dr. Juan Li, Dr. Si-Yuan Xu and Jian-Xin Chen (Institute of Entomology, Guizhou University); Dr. Wen-Ge Dong (Dali University) for their kind help in many ways. We are also very grateful to Wen-Yu Song, Rong Fan, ZhiWei Zhang, Chen-Fu Zhao, Ke-Yu Mao, Yun-Ji Zou for their special contribution to the field investigations and the collection of gamasid mites. This study was funded by the National Natural Science Foundation of China to XianGuo Guo (No. 81460313 and 81672055).

\section{Statement of conflict of interest}

The authors declare that there is no conflict of interests regarding the publication of this article.

\section{REFERENCES}

Baker, E.W., Evans, T.M., Gould, D.J., Hull, W.B. and Keegan, H.L., 1956. A manual of parasitic mites 
of medical or economic importance. National Pest Control Association Inc, New York

Chen, G. and $\mathrm{Xu}, \mathrm{H} .$, 1995. Ticks and diseases. In: Ticks and mites in human diseases (eds. Y. Meng, C. Li and G. Liang). University of Science and Technology of China Press, Hefei, pp. 75-116.

Deng, G.F., Wang, D.Q., Gu, Y.M. and Meng, Y.C., 1993. Economic insect fauna of China. Fasc 40, Acari, Dermanyssoidea. Science Press, Beijing.

Evans, G.O., 1963. Observations on the chaetotaxy of the legs in the free-living Gamasina (Acari: Mesostigmata). Bull. Br. Mus. (Nat. Hist.) Zool., 10: 275-303.

Frolova, G.I., 1990. Gamasid mites as ectoparasites of rodents in Volgogradskaya Oblast. In: Advances in medical entomology and acarology in the Soviet Union (ed. G.S. Medvedev). Akad. Nauk SSSR, Zool, Institut, Vsesoyuzn. Entomol. Obshchestvo, pp. 178.

Guo, X.G., Speakman, J.R., Dong, W.G., Men, X.Y., Qian, T.J., Wu, D., Qin, F. and Song, W.Y., 2013. Ectoparasitic insects and mites on Yunnan red-backed voles (Eothenomys miletus) from a localized area in southwest China. Parasitol. Res., 112: 3543-3549. https://doi.org/10.1007/s00436013-3537-6

Huang, L.Q., Guo, X.G., Wu, D., Wang, Q.H. and Zhou, D.H., 2010. Ecological distribution and diversity of gamasid mites on small mammals in Yunnan, China. Acta Parasitol. Et Med. Entomol. Sinica, 17:16-23

Huang, L.Q., Guo, X.G., Speakman, J.R. and Dong, W.G., 2013. Analysis of gamasid mites (Acari: Mesostigmata) associatedwith the Asian house rat, Rattus tanezumi (Rodentia: Muridae) in Yunnan Province, southwest China. Parasitol. Res., 112: 1967-1972. https://doi.org/10.1007/s00436-0133354-y
Johnston, D.E. and Moraza, M.L., 1991. The idiosomal adenotaxy and poroidotaxy of Zerconidae (Mesostigmata: Zerconina). In: Modern acarology (eds. F. Dusbábek and V. Bukva).SPB Academic Publishing, The Hague, pp. 349-356.

Khan, A.K., Bashir, M.H., Khan, B.S. and Javed, N., 2017. Biodiversity of soil inhabiting Mesostigmata (Arachnida:Acari) from different Agto-Ecological zone of Punjab, Pakistan. Pakistan J. Zool, 49: 677683.

Lindquist, E.E. and Evans, G.O., 1965. Taxonomic concepts in the Ascidae, with a modified setal nomenclature for the idiosoma of the Gamasina (Acarina: Mesostigmata). Mem. Ent. Soc. Can., 97: 5-66. https://doi.org/10.4039/entm9747fv

Lindquist, E.E., Krantz, G.W. and Walter, D.E., 2009. Order Mesostigmata. In: A Manual of Acarology (Eds. Krantz, G.W. and Walter, D.E.) 3rd Edition. Texas Tech. University Press, Lubbock, pp. 124232.

Nadchatram, M. and Ramalingam, S., 1974. Dermatitis caused by Ornithonyssus bacoti (Hirst, 1913). Southeast Asian J. Trop. Med. Publ. Hlth., 5: 150.

Pan, Z.W. and Deng, G.F., 1980. Economic insect fauna of China. Fasc 17 Acariformes, Gamasina. Science Press, Beijing.

Sandosham, A.A. and Nordin, K., 1967. Animal parasites of animals which affect man in Malaysia. Med. J. Malaya, 22: 16-25.

Song, G., 1999. Epidemiological progresses of hemorrhagic fever with renal syndrome in China. Chin. med. J., 112: 472-477.

Wilson, D.E. and Reeder, D.M., 2005. Mammal species of the World. A taxonomic and geographic reference, $3^{\text {rd }}$ edn. Johns Hopkins University Press.

Zemskaya, A.A., 1973. Parasitic gamasid mites and their medical significance. Meditsina, Moscow, pp. 167. 